\title{
THE INTER-RELATIONSHIPS OF CERTAIN JASSOID GENERA (JASSOIDEA, HOMOPTERA)
}

\author{
By J. W. Evans
}

Department of Agriculture, Hobart, Tasmania

As a result of a study of Australian leaf-hoppers which has extended over several years, certain conclusions have been reached concerning the classification of this group of insects that disagree with the generally accepted ideas on the subject. These conclusions have already been published (Evans, 1939). The purpose of the present paper is to draw attention to the new proposed classification in so far as it affects certain genera represented in the North American fauna. It is not intended to repeat the arguments on which the new system is based, nor to give lengthy diagnoses of characters. Instead, recourse is made to brief comparisons supported by illustrations. These it is hoped will suffice to stimulate interest in the new proposals, and help to pave the way to a system based more on genetic affinity than on superficial characteristics.

The genera concerned are, Bythoscopinae: Bythoscopus Germ., Agallia Curtis, Idiocerus Lewis, Macropsis Lewis, Oncopsis Burm., Neopsis Oman ; Gyponinae: Gypona Germ., Penthimia Germ., Xerophloea Germ.; Jassinae: Jassus Fabr., Euscelis Brullé, Dorycephalus Kirsch., Hecalus Stål, Spanbergiella Sign., Parablocratus Fieb., Nionia Ball; Koebelinae: Koebelia Baker.

Following Baker (1923), it has been found convenient to regard each of the more distinct groups of leaf-hoppers as a family unit, and the re-arrangement of the above genera into families on the basis of my system results in the following groupings :

$$
\begin{aligned}
& \left\{\begin{array}{l}
\text { Gyponinae } \\
\text { Gyponini-Gypona }
\end{array}\right. \\
& \text { Bythoscopidae } \text { Bythoscopinae Bythoscopus } \\
& \text { Penthimiinae }\left\{\begin{array}{l}
\text { Penthimiini-Penthimia } \\
\text { (Thaumatoscopini*) }
\end{array}\right.
\end{aligned}
$$

* Not represented in North America. 
Euscelidae, Euscelis. Agalliidae, Agallia. Macropsidae, Macropsis, Oncopsis, Neopsis. Idioceridae, Idiocerus. Jassidae, Jassus. Thymbridae, Nionia. Ledridae, Dorycephalus, Xerophloea. Stenocotidae, Koebelia.

Whilst certain of the proposed changes, such as the separation of Euscelis, Idiocerus and Jassus, have been suggested previously by other workers, others, in particular the association of Bythoscopus, Hecalus, Penthimia and Gypona, are original, and may at first sight appear absurd. If in time the alterations proposed should become accepted in whole or even in part, it will not be the first occasion on which a

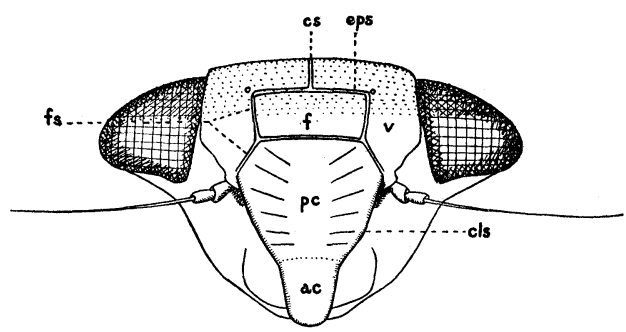

Figure 1. Head of a nymph of Tartessus sp. ac., ante-clypeus; pc., post-clypeus; f., frons; cls., clypeal suture; fs., frontal suture; v., vertex; cs., coronal suture; eps., epicranial suture.

knowledge of the Australian representatives of a group of organisms has led to a radical change being effected in the basic classification of the same group in other faunal zones.

The usual arrangement of the various genera into subfamilies on the basis of the position of the ocelli is clearly artificial and several workers have stressed this fact in the past. Nevertheless, whilst the position of the ocelli may be of little significance, the shape and structure of the head as a whole affords the most reliable single diagnostic character. Because certain terms will be used in referring to the head that are not commonly employed, a figure of the head of a nymph of Tartessus sp. is given with certain of the sutures and sclerites indicated (Fig. 1). This particular insect has been chosen for illustration as the front is present as a separate sclerite. With the backward migration of the dilator muscles of the sucking pump, the epistomal suture, which separates the clypeus from the frons, disappears; 
such a condition is found in all adult leaf-hoppers. The sclerite made up in part of the frons and in part of the postclypeus, will be referred to as the fronto-clypeus. It may be entirely central in position or extend onto the crown, and may, or may not, be directly continuous with the vertex. The morphology of the head of Homoptera has been fully discussed in three recent publications (Spooner, 1938; Evans, 1938; Snodgrass, 1938.)
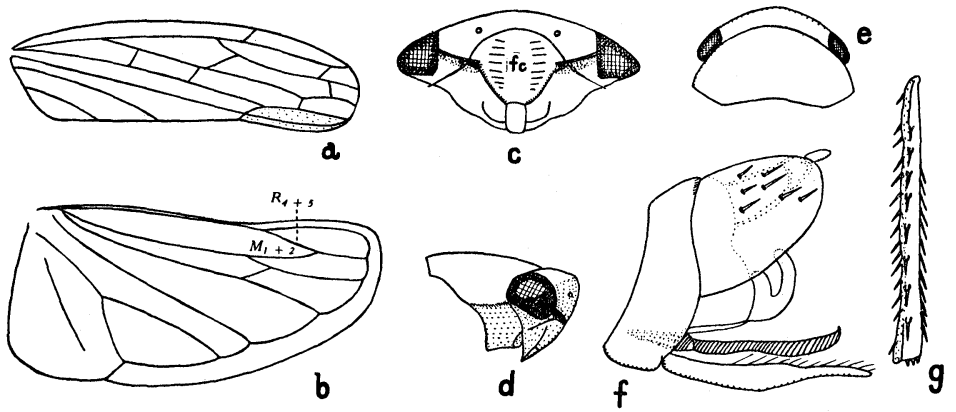

Figure 2. a, b, e, Eurinoscopus punctatus; c, d, g, Bythoscopus lanio; f, Eurinoscopus sp., male genitalia; fr., fronto-clypeus.

\section{BYTHOSCOPIDAE}

The principal features of the external structure of Bythoscopus lanio (L.) and Eurinoscopus spp. are shown in Figure 2. Eurinoscopus Kirk. is an Australian genus which according to Oman (1936) is synonymous with Bythoscopus. In Figure 3 the corresponding parts of Reuteriella flavescens Sign. are illustrated. This is an Australian leaf-hopper, which, because of the marginal position of the ocelli, would presumably be placed in the Jassinae by most Hemipterists. It is unnecessary to do more than draw attention to the very close similarity between the two groups of illustrations. The differences are, that in Bythoscopus, a frontal and an epicranial, but not a coronal, suture are retained, the reverse being the case with Reuteriella. The ocelli in the two genera are in identical positions, as is shown by a comparison of Fig. 2, d with Fig. 3, e, except that the backward extension of the muscles of the sucking-pump and the accompanying 
flattening and production of the head have changed their aspect in Reuteriella.

The process arising from the ventral internal margin of the pygophore of the male genitalia of $R$. flavescens is secondary, and of only specific value as a diagnostic character. Quite apart from structure, in appearance, habits and coloration, Reuteriella spp. and Eurinoscopus spp. are very similar.

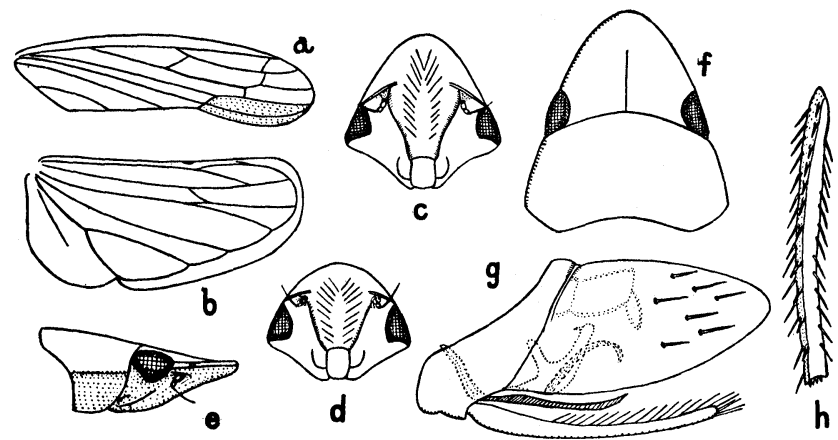

Figure 3. Reuteriella flavescens; c, 우 d, ô.

If it is accepted that Reuteriella should be grouped with Bythoscopus rather than in the Jassinae, there seems to be no good reason why Hecalus, Parablocratus and Spanbergiella should not also be placed in the Bythoscopidae. Although species in these genera may lack the character of having $\mathbf{R}_{4+5}$ fused apically with $\mathrm{M}_{1+2}$ in the wing, all have similarly shaped heads and pronota and flattened hind tibiae with an almost identical armature of spines. Furthermore, the tegminal venation is not basically dissimilar. Figures are given (Fig. 4, d-g) of Spanbergiella vulnerata (Uhl.) and Parablocratus glaucescens Fabr. (a Tunisian species).

The relationship of Gypona to Bythoscopus is not quite so apparent, but it is believed that Krisna strigicollis (Spin.), which occurs in Borneo (Fig. 5 a-e), is close to Reuteriella. A comparison of these figures with Figure $5 a_{1}-d_{1}$ suggests that the two genera are not far removed from each other. Moreover, if Penthimia is grouped with Gypona, as is usually done, then the case for the inclusion of Gypona in the Bythoscopidae is strengthened. A comparison of the head of 
Bythoscopus and Penthimia, illustrated in Figures 2, c and $4, \mathrm{~b}$ respectively, will show that the genera resemble each other in essential head structure. The occurrence of the hindmost part of the fronto-clypeus on the crown in Penthimia is a purely secondary feature brought about by the production and inflation of the fronto-clypeus. The Thaumatoscopini are a tribe comprising Australian genera that show complete gradation between species with ventral ocelli and rounded heads, and others with dorsal ocelli and spatulate heads.
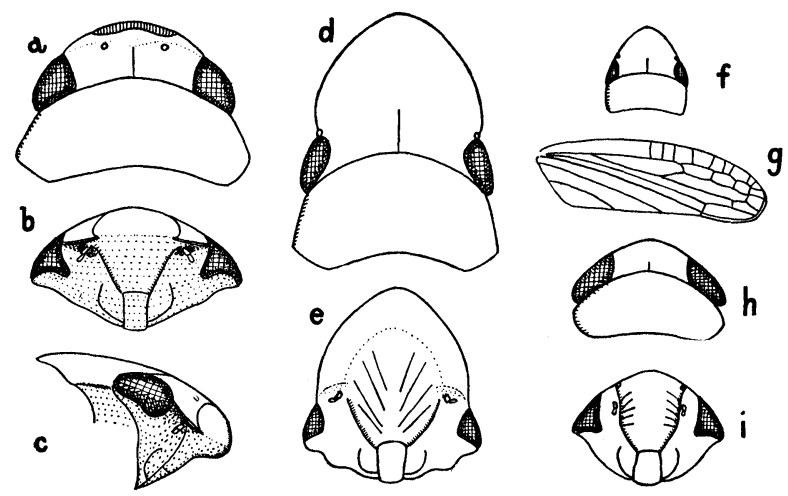

Figure 4. a-c, Penthimia americana; d, e, Spanbergiella vulnerata; f, g, Parablocratus glauscens; h, i, Thamnotettix cockerelli.

\section{EUSCELIDAE}

This family, which comprises genera related to Euscelis, such as Thamnotettix Zett., Eutettix Van D. and Deltocephalus Burm., though distinct from the Bythoscopidae, is probably an offshoot from it. It is almost certain that Hecalus, Parablocratus and Spanbergiella are nearer to Bythoscopus than to Euscelis. For the purpose of comparison, figures are given of Thamnotettix cockerelli Ball. (Fig. 4, h, i).

\section{Agalliidae}

Agallia does not closely resemble Bythoscopus in shape, size, or coloration, nor in a single character of any significance; neither do any of the numerous genera usually asso- 
ciated with Agallia. For comparison with the illustrations of Bythoscopus, figures are given of Euragallia farculata (Osb.) (Fig. 6, g-i).
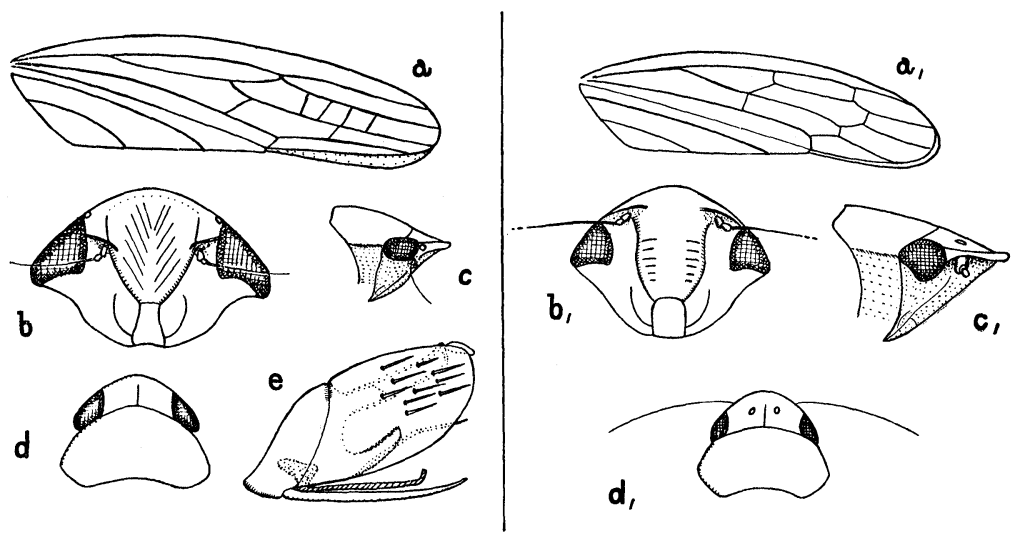

Figure 5. a-e, Krisna strigicollis; a, Gypona scarlatina, b-d, Gypona 8-lineata.

\section{MACROPSIDAE}

Macropsis and Oncopsis likewise present no essential features in common with Bythoscopus. Oman (1936) has suggested that Neopsis Oman is intermediate in character between Macropsis and Bythoscopus. Through the kindness of Mr. Oman I have been able to examine a specimen of the genotype, $N$. elegans Van D., and am of the opinion that without any doubt it should be placed in the Macropsidae, any resemblance it may have to Bythoscopus being purely superficial. All the Macropsidae have a character in common that does not occur in representatives of other families. This is, that when the muscle impressions of the suckingpump are visible on the fronto-clypeus, they are invariably confined with a pair of crescent-shaped markings.

\section{IDIOCERIDAE}

In 1936 Oman removed Idiocerus and related genera from the Bythoscopinae and referred them to the Eurymelinae. Whilst in agreement with the separation, I do not support 
the new combination. The following characters which occur in all the Eurymelidae are not found in Idiocerus: in the head the epicranial sutures are invariably retained; in the tegmen the media has always two, and sometimes three, distinct branches; in the male genitalia the aedeagus is not in direct contact with the basal plates. Quite apart from these features, the Eurymelidae differ from the Idioceridae in shape, coloration and habits. Figures of Idiocerus dolosus Ball (Fig. 6, d-f), are given for comparison with those of Bythoscopus.
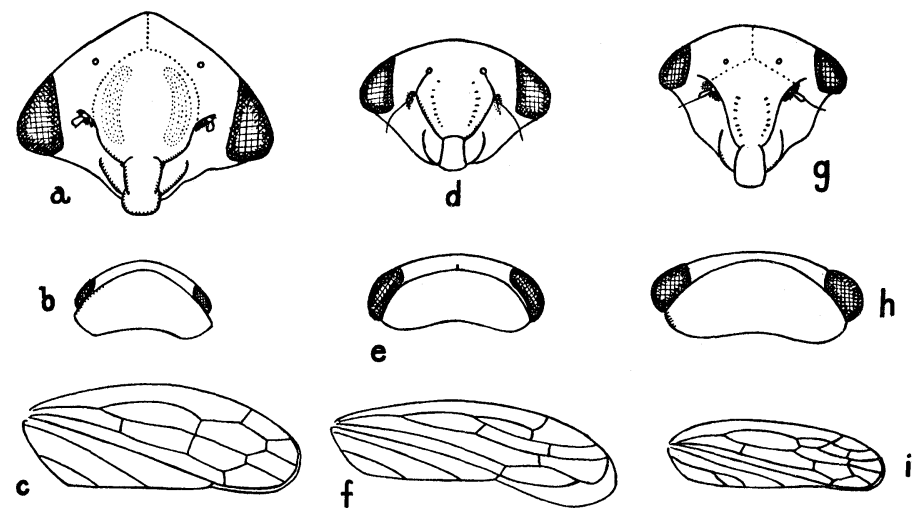

Figure 6. a, Macropsis tasmaniensis; b, c, Oncopsis distinctus; d-f, Idiocerus dolosus; g-i, Euragallia furculata.

\section{JASSIDAE}

Figures are not given of a representative of this family, but there seems no good reason why genera such as Jassus Fabr. and Tharra Kirk. should be associated with forms such as Euscelis and Thamnotettix.

\section{THYMBRIDAE}

Oman, in referring to Nionia Ball, states that it was correctly placed by Ball as a relative of Tartessus Stål, but was more closely related to Thymbris Kirk. and Epipsychidion Kirk. I have not had an opportunity of examining a specimen of Nionia, but, if it is closely related to Thymbris, it is 
presumably a member of the Thymbridae, which contains several Australian genera and a single New Zealand genus. Thus it cannot be very close to Tartessus. The Tartessidae contain a number of genera which now occur in Australia, New Guinea, the Phillipines, New Caledonia and Mysol and which all have certain unique characteristics. One of these is the continuation of the ambient vein of the wing onto the anal area. The tegmen of Mesojassoides gigantea Oman from Cretaceous deposits of Colorado figured by Oman (1937), is very similar to that of a present-day Tartessus, and suggests that this family had a wider distribution at one time than it has at present.
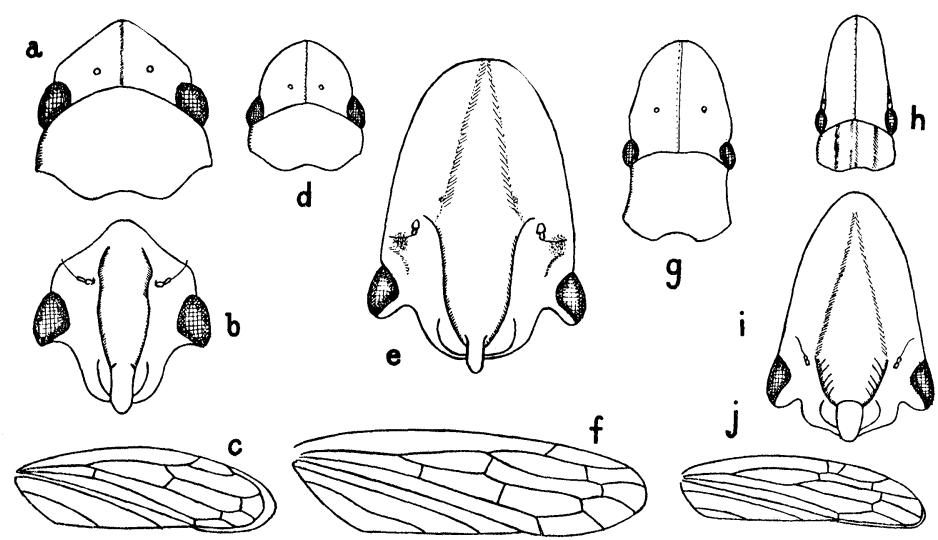

Figure 7. a-c, Xerophloea viridis; d, f, Rubria sanguinea; e, g, Ledropsis crocina; h-j, Dorycephalus platyrhynchus.

\section{LEDRIDAE}

Xerophloea is usually placed in the Gyponinae because it has dorsal ocelli and is clearly not close to Cicadella Latr., Dorycephalus having marginal ocelli is placed in the Jassinae. Both genera are much closer to genera in the Ledridae, as may be seen in Figure 7, where figures of the Australian Ledrids Rubria sanguinea Stål and Ledropsis crocina Dist. are placed beside others of Xerophloea viridis (Fabr.) and Dorycephalus platyrhynchus Osb. 


\section{STENOCOTIDAE}

Baker (1923) considered Koebelia to be intermediate between Ulopa Fall. and Paropia Germ. on the one hand, and Stenocotis Stål on the other. For reasons previously given, (Evans, 1939), there would seem to be no justification for placing Koebelia californica Baker in a separate family, when it is essentially a Stenocotid.

\section{REFERENCES}

Baker, C. F. 1923. The Jassoidea related to the Stenocotidae. Phillipine Journ. Sci. 23(4) : 345.

Evans, J. W. 1938. The Morphology of the Head of Homoptera. Papers Roy. Soc. Tas. 1937-38:1.

Evans, J. W. 1939. A Contribution to the Study of the Jassoidea. Papers Roy. Soc. Tas. 1938-39: 19.

Oman, P. W. 1936. A Generic Revision of American Bythoscopinae and South American Jassinae. Bull. Univ. Kansas 37(14) : 343.

Oman, P. W. 1937. Fossil Hemiptera from the Fox Hills Sandstone (Cretaceous of Colorado). Journ. Palaeontology 11(1): 38.

Snodgrass, R. E. 1938. The loral plates and hypopharynx of Hemiptera. Proc. Ent. Soc. Washington 40(8): 228.

Spooner, C. S. 1938. The Phylogeny of the Hemiptera based on a study of the Head Capsule. Illinois Biological Monographs 16(3). 

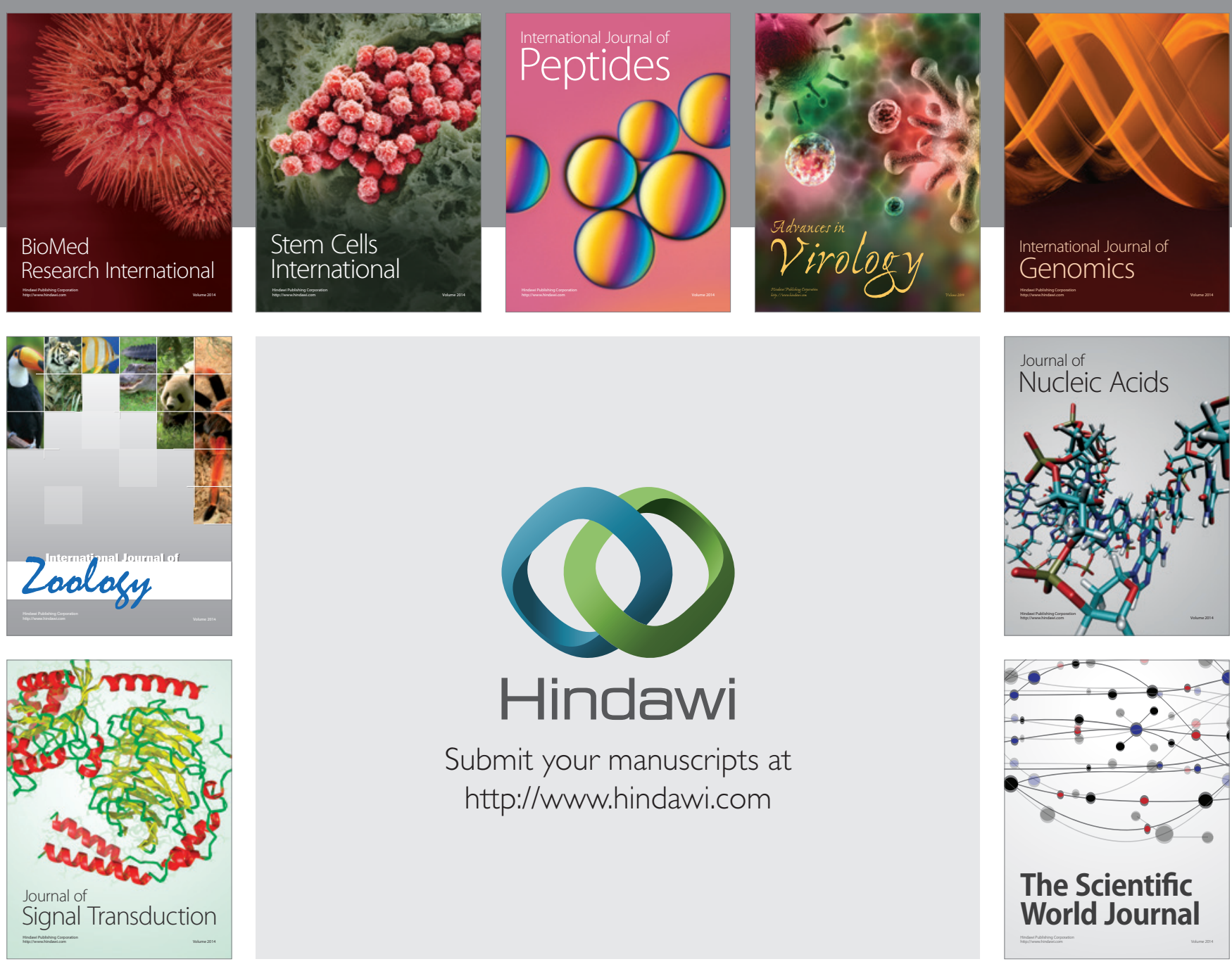

Submit your manuscripts at

http://www.hindawi.com
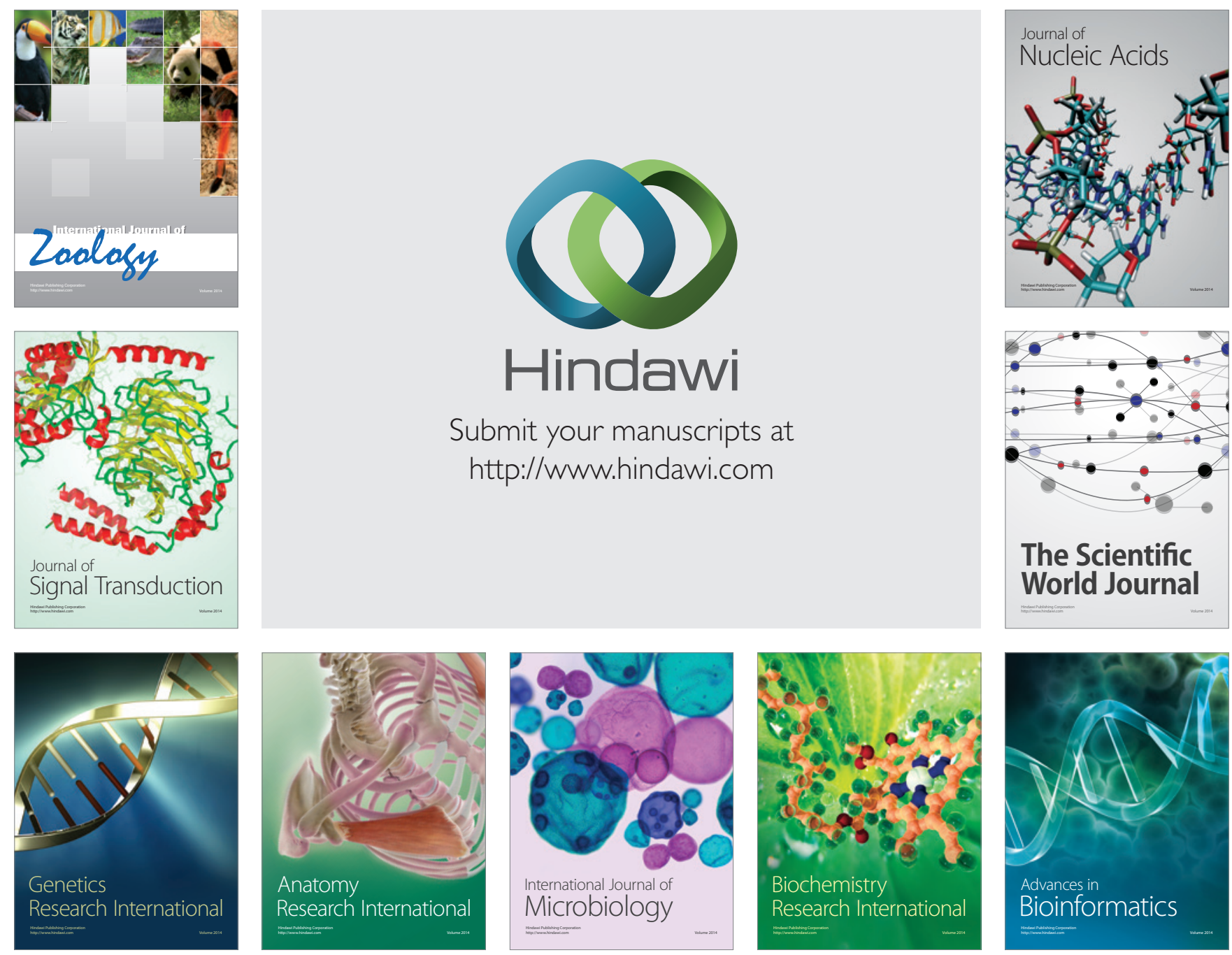

The Scientific World Journal
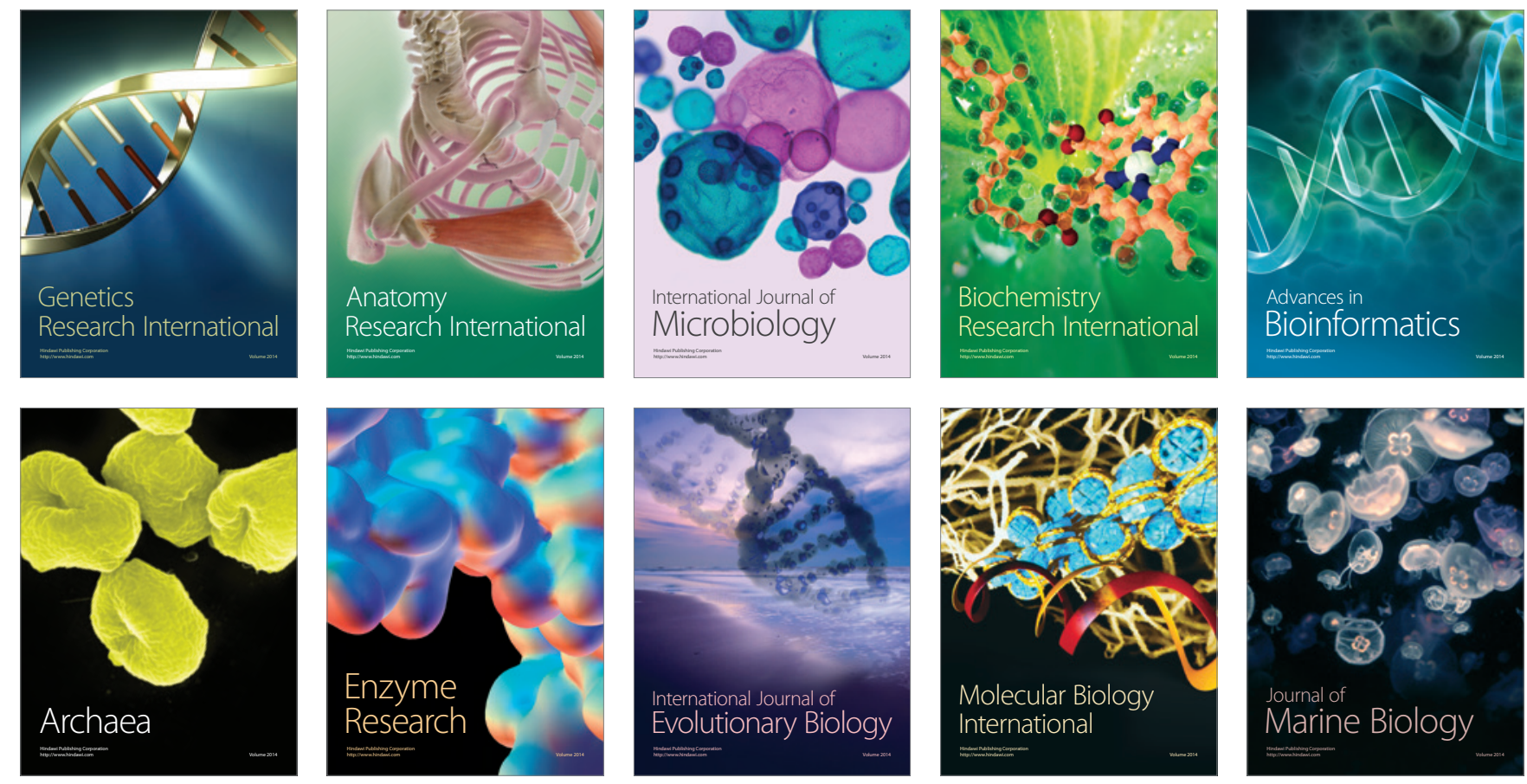